\title{
Extraction of amplifiable DNA from embalmed human cadaver tissue
}

\author{
Lindsay Gielda ${ }^{*}$ and Stefanie Rigg
}

\begin{abstract}
Objective: The expansion of molecular techniques in medical diagnosis, forensics, and education requires the development of improved techniques of DNA extraction from fixed tissues. Cadaver tissues are not commonly used for genetic analysis due to DNA degradation resulting from the embalming fixation. Modification of existing techniques of tissue disruption combined with phenol-chloroform treatment was done to produce an efficient method of extracting amplifiable DNA of high quality and quantity from non-paraffin embedded embalmed cadaver tissue.

Results: Tissues (cerebellum, cerebral cortex, heart, and bone) from four cadavers were used to develop a procedure for DNA isolation, which includes a high heat treatment. The location and age of the tissue had a significant effect on the quantity of DNA recovered. Targeted PCR amplification of the Apolipoprotein gene was used to assess the efficacy of genotypic analysis from the recovered DNA. We report the development of a simple, reliable, and low-cost method of DNA isolation utilizing brain tissue from embalmed tissues that could be used for PCR amplification and genetic analysis.
\end{abstract}

\section{Introduction}

Significant medical research and genetic analysis is dependent on extraction of DNA from human tissues. Formalin-fixed paraffin embedding (FFPE) of biological tissues is the most common technique for pathological testing and offers preservation of protein, DNA, and RNA molecules. Isolation of DNA from FFPE tissues has been used for numerous purposes including genetic studies or use in forensic cases. However, the quantity and quality of recovered DNA is highly variable and dependent on tissue type and extraction procedure.

Utilization of embalmed cadaver tissues for DNA isolation is rarely used due to poor quality of extracted material, as a result of embalming fixatives. The embalming process exposes tissues to several chemicals including glutaraldehyde and formalin (aqueous formaldehyde), which induces intra- and intermolecular crosslinking [14]. Formaldehyde is a potent fixative that results in covalent protein-protein and protein-DNA conjugates [2-4]. Due to this extensive cross-linking, standard extraction

\footnotetext{
*Correspondence: Igielda@pnw.edu

Department of Biological Sciences, Purdue University-Northwest, 1401 S. US 421, Westville, IN 46391, USA
}

protocols from formalin-fixed tissues results in highly fragmented DNA. For example, DNA extracted from FFPE tissues typically ranges between 50 and 300 bp in length, leading to difficulty in amplifying high molecular weight DNA for use in genotypic studies [5].

Multiple DNA extraction methods and commercially available kits exist, and are modified dependent on tissue type with variable success rates $[6,7]$. The preferred tissue for DNA extraction for genomic studies is the use of FFPE, of which several protocols have been developed [5, 8-14]. However, the development of a reliable DNA isolation technique from embalmed tissues would provide an alternative source of genetic material for post-mortem identification and diagnostic purposes, as well as significantly expand the sample size for genetic studies in identification of genetic markers of disease.

An example of a genetic maker of disease is the Apolipoprotein (APOE) gene. Apolipoprotein E protein mediates the removal of plasma lipoproteins, and is recognized as a major contributor of neuronal function. In the brain, secreted apolipoprotein binds specific lipids and plays a role in the brain's response to injury. Deposition of amyloid $\beta$ plaques is a hallmark of Alzheimer's disease and is influenced by apolipoprotein-mediated 
lipid homeostasis of amyloid $\beta$. Three polymorphisms of APOE exist (E2, E3, E4) that differ by a single amino acid, and influence the development of Alzheimer's [15, 16]. The APOE3 isoform is the predominant allele, with the APOE4 allele associated with an increased risk of Alzheimer's disease, and the APOE2 allele providing a protective effect against Alzheimer's, leading to longevity [17, 18].

This research reports on the development of a simple and low-cost method of DNA isolation utilizing brain tissue from embalmed cadaver tissue. Modification of preexisting phenol-chloroform extraction methods enabled the extraction of quantifiable DNA that was used for genotyping of the APOE allele.

\section{Main text \\ Methods \\ Cadaver donors}

Cadavers were embalmed by the Cincinnati University College of Medicine using a standard two-site injection method and embalmed with a mixture of formaldehyde, glutaraldehyde and methanol. Tissues in this study were removed and stored in $10 \%$ formalin at room temperature for further analysis. Tissues were identified based on their academic year of dissection and sex.

\section{A549 Cells}

A549 cells were cultured in F12 Nutrient Medium with L-glutamine (ATCC cat\#30-2004), 10\% Fetal Bovine Serum (FBS) (ATCC cat\#30-2021) and penicillin-streptomycin (ATCC cat\#30-2300) at $37{ }^{\circ} \mathrm{C}$ in a humidified $5 \% \mathrm{CO}_{2}$ incubator. Cells were collected following three washes with phosphate buffered saline (PBS), followed by incubation with $1 \times$ Trypsin/EDTA solution (ATCC cat\#30-2101) until detachment.

\section{DNA Extraction and quantification}

Dissected tissue samples (50-60 mg) or cultured A549 cells were manually homogenized in PBS using a pestle in Nasco Whirl-paks (Fisher cat\#01-812-5M). Tissue were washed $2 \times$ with PBS, and resuspended in Tris buffer (10 mM Tris- $\mathrm{HCl}, \mathrm{pH} 8.5)$. This mixture was vortexed, heated at $95{ }^{\circ} \mathrm{C}$ for $15 \mathrm{~min}$, and cooled to room temperature. A standard phenol-chloroform extraction was performed. Briefly, an equal volume of 25:24:1 phenol/ chloroform/isoamyl alcohol (Sigma-Aldrich cat\#P2069) was added, vortexed, and centrifuged $(5 \mathrm{~min}, 13 \mathrm{~K} \mathrm{rpm}$, $4{ }^{\circ} \mathrm{C}$ ). The aqueous phase was retained, and an equal volume 24:1 chloroform/isoamyl alcohol (Sigma-Aldrich cat\#C0549) was added, vortexed, and centrifuged. To elute the DNA from the retained aqueous phase, $3 \mathrm{M}$ ammonium acetate was added to a final concentration of $0.75 \mathrm{M}$, and $2.5 \times$ volume of $95 \%$ ethanol was added to precipitate the DNA. Samples were centrifuged to pellet DNA $\left(20 \mathrm{~min}, 13 \mathrm{~K} \mathrm{rpm}, 4{ }^{\circ} \mathrm{C}\right)$. The pellet was washed $2 \times$ with $80 \%$ ethanol, suspended in $50 \mu \mathrm{l}$ of TE buffer and stored at $-20^{\circ} \mathrm{C}$. DNA was quantified via Nanodrop spectrophotometry (ThermoFisher).

\section{APOE PCR amplification and digest}

APOE polymorphisms were detected as previously described [19]. Briefly, genomic DNA was amplified using

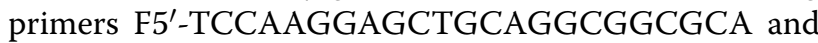
R5'-GCCCCGGCCTGGTACACTGCCA (IDT) to yield a 218-bp DNA fragment using GoTaq polymerase (Promega cat\#M7132). Amplified DNA was digested with HaeII and AflIII (NEB cat\#R0107S and R0541S) for $2 \mathrm{~h}$ at $37{ }^{\circ} \mathrm{C}$ and resolved on a $4 \%$ agarose gel. Samples were classified based on size; 145, 168, and 195-bp fragments specific for APO E3, E2, and E4.

\section{Statistical analysis}

All data are presented as the means and standard deviations. Student $t$ test was used to assess the statistical significance of group differences. $\mathrm{p}$ values $\leq 0.01$ were accepted as significant $(*)$.

\section{Results}

\section{Tissue extraction and digestion method development}

Tissue, including the cerebellum, cortex (grey and white matter), heart, and bone, were collected from cadavers ranging from 1 to 3 years in age. Extractions focused on tissues that are commonly used for DNA extraction or contain a high density of nuclei, and thus genomic DNA, such as brain and heart [3].

A procedure was developed that would aid in the removal of cross-linked proteins from DNA due to fixatives. Several variables were initially tested to optimize extraction, followed by a standard phenol-chloroform extraction. Variables not included in the final method resulted in less than $1 \mathrm{ng} / \mu \mathrm{l}$ of DNA and are described in Additional file 1: Table S1. A significant increase in DNA quantity and quality was observed when tissues were washed $2 \times$ with PBS, followed by a 15 -min incubation at $95{ }^{\circ} \mathrm{C}$ prior to phenol/chloroform extraction and was therefore chosen as the preferred method.

\section{Quantification of DNA from variable tissue sources}

To assess tissue variability, DNA was extracted from the cerebellum, cerebral cortex (grey and white matter), heart, and bone from four cadavers. Variable quantities were recovered, with the highest yield from the cerebel$\operatorname{lum}(463.35 \mathrm{ng} / \mu \mathrm{l})$ and heart yielding the lowest $(7.9 \mathrm{ng} /$ ul) (Table 1). As heart and bone tissues are common sources for DNA isolation, these tissues were used for comparison in DNA quantification analysis $[1,3,7]$. 
Table 1 DNA yield is dependent on tissue type

\begin{tabular}{lcl}
\hline Tissue & $\mathbf{n g} / \boldsymbol{\mu l}$ & $\mathbf{2 6 0 / 2 8 0}$ \\
\hline Cerebellum & $463.35( \pm 316.98)$ & $1.90( \pm 0.09)$ \\
Cerebral cortex (grey matter) & $66.468( \pm 36.37)$ & $1.83( \pm 0.10)$ \\
Cerebral cortex (white matter) & $15.3( \pm 12.9)$ & $1.71( \pm 0.15)$ \\
Heart & $7.9( \pm 7.59)$ & $1.54( \pm 0.29)$ \\
Bone & $32.95( \pm 27.6)$ & $1.75( \pm 0.18)$ \\
Cerebellum & & \\
15/16F & $740.7( \pm 152.83)$ & $1.95( \pm 0.09)$ \\
15/16M & $546.87( \pm 345.32$ & $1.89( \pm 0.11)$ \\
14/15M & $137.47( \pm 54.84)^{* \mathrm{~T}}$ & $1.81( \pm 0.15)$ \\
13/14M & $55.3( \pm 21.3)^{* \mathrm{~T}}$ & $1.84( \pm 0.09)$ \\
Cerebral cortex (grey matter) & & \\
15/16F & $103.7( \pm 21.92)$ & $1.85( \pm 0.13)$ \\
15/16M & $78.85( \pm 27.36)$ & $1.94( \pm 0.10)$ \\
14/15M & $26.95( \pm 7.42)^{* \mathrm{~T}}$ & $1.82( \pm 0.07)$ \\
13/14M & $14.95( \pm 5.16)^{* \mathrm{~T}}$ & $1.87( \pm 0.10)$ \\
\hline
\end{tabular}

Quantification $(\mathrm{ng} / \mathrm{\mu l})$ and absorbance $260 / 280$ ratio of DNA isolated from the indicated tissue sources from four cadaver donors. Mean and standard deviation are reported. These results are an average of a minimum of three independent extractions. Student t-test was used to indicate significance between groups ( ${ }^{*} \mathrm{p} \leq 0.01$ compared to $15 / 16 \mathrm{~F}$ and ${ }^{\mathrm{T}} \mathrm{p} \leq 0.01$ compared to $15 / 16 \mathrm{M}$ )

Time of storage was hypothesized to affect the quality of isolated DNA. To assess this, DNA was extracted from the cerebellum and cerebral cortex (grey matter) of each cadaver. The most recent cadavers (15/16F and 15/16M) had significantly higher yields $(\mathrm{p}<0.01)$ from both the cerebellum and cerebral cortex tissue, each compared to older tissues, indicating that storage in $10 \%$ formalin affects DNA integrity and recoverability over time (Table 1). Additionally, the size of the DNA recovered was affected by the age of the tissue, with DNA species up to $1 \mathrm{~Kb}$ only isolated from tissues in the $15 / 16$ Female cadaver (Fig. 1).

\section{Identification of APOE polymorphisms in cadaver donors}

The inability for amplification of extracted DNA from embalmed tissues is the limiting factor for use in genetic applications. The DNA isolated from the cerebellum and cerebral cortex were chosen for subsequent genotypic analysis due to the quantity and size of DNA recovered. Gel electrophoresis of extracted DNA revealed a range of DNA species, up to $1 \mathrm{~Kb}$, suggesting that PCR amplification would be possible. Amplification of APOE was chosen to examine the efficacy of this protocol and the resultant 218 bp APOE amplicon was observed in all DNA samples (Fig. 2a).

Subsequent restriction enzyme digestion produced cleavage products consistent with the various polymorphisms from previous reports [19]. The genotypes of the

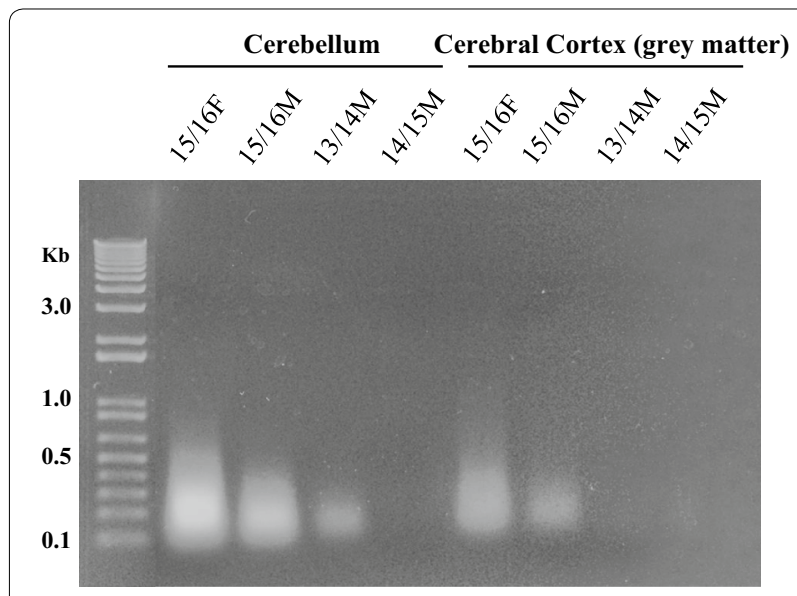

Fig. 1 Amplification of Extracted DNA. Gel electrophoresis of the recovered DNA from the cerebellum and cerebral cortex (grey matter) from four cadaver samples. Extraction of DNA from A549 cells was used as a positive control for PCR amplification. DNA species isolated from cadaver tissues range from $50 \mathrm{bp}$ to $1 \mathrm{~Kb}$

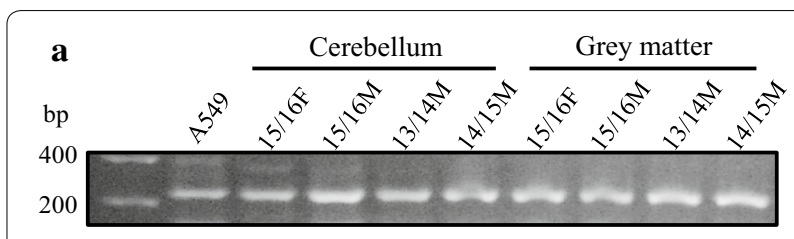

b
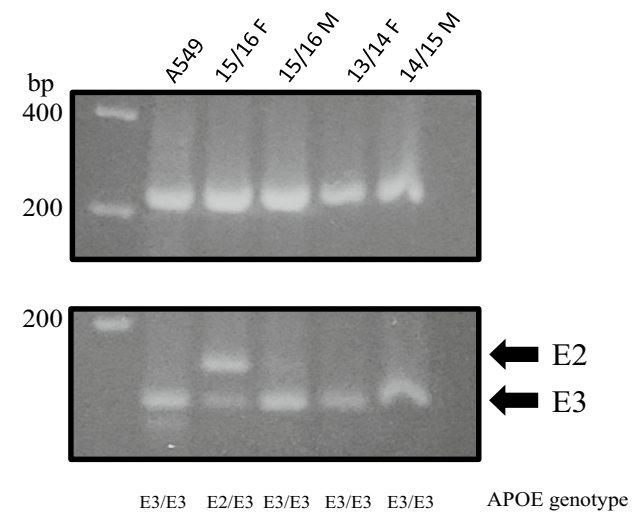

Fig. 2 APOE Genotypic Analysis of Cadaver. a PCR amplification of APOE was observed in all the DNA samples for cerebellar tissue yielding a 218-bp fragment. DNA extracted from A549 cells was used as a positive control. b APOE gene PCR amplification (top) and restriction enzyme digestion (bottom) produced cleavage products consistent with the various polymorphisms revealing the individual genotype for each sample. Four APOE3/E3 genotypes (A549, 15/16M, 13/14F, 14/15M) and one APOE2/E3 (15/16F) were identified

cadaver donors were identified from this analysis, revealing three individuals with the E3/E3 genotype and one with an E2/E3 genotype (Fig. 2b). 


\section{Discussion}

Molecular research and diagnostic pathology have typically utilized FFPE tissues due to availability. While numerous studies have developed methods for DNA extraction from FFPE tissues, the efficiency is dependent on several variables, including tissue type, age, fixation methods, and methods of recovery [20-23]. The development of a technique that efficiently recovers DNA from non-paraffin embedded tissues, such as cadavers, would significantly expand the available resources for genetic research and forensic cases. The protocol described herein utilizes high heat treatment for the extraction of high quantities of amplifiable DNA from embalmed tissue.

Following death, cellular decay occurs rapidly, inducing oxidative and hydrolytic damage to DNA. Embalming preserves tissues by utilizing fixatives to induce molecular cross-linking and slowing decay. Subsequent extraction attempts results in highly degraded DNA due to the chemicals used. A digestion step utilizing proteinase $\mathrm{K}$ is commonly utilized in extraction procedures, but with embalmed tissues, this reduced the DNA yield to less than $1-5 \mathrm{ng} / \mu \mathrm{l}$ with the DNA species resolving at $\sim 50 \mathrm{bp}$ by gel electrophoresis. This is thought to be due to the DNA-nucleosome crosslinking, as nucleosomes consist of $147 \mathrm{bp}$ of DNA bound to a histone octamer with a variable linker region of 20-90 bp in length [24]. Fixative mediated protein-crosslinking and subsequent DNA extraction would result in the removal of cross-linked nucleosome DNA but retention of linker DNA species approximately $50 \mathrm{bp}$ in length. Recent studies identified high heat treatment of FFPE tissues as a critical step to dissociate DNA from its associated nucleosome proteins $[13,14]$. A subsequent heat-only method was adopted to denature proteins of the nucleosome facilitating the release of DNA, and allowing for the isolation of larger DNA species.

Tissue type and time of preservation had a significant impact on the quantity and quality of DNA extracted. The yield of DNA was found to be significantly higher in the cerebellum and cerebral cortex grey matter. There was also a correlation between post-mortem age of the brain and quantity of DNA extracted, as the most recently preserved tissue, from the 2015/2016 cadavers yielded significantly higher quantity of DNA. Similar results were observed in methods for isolation of amplifiable DNA from FFPE tissue samples $[9,12,14,25,26]$.

Results from studies that analyze DNA extraction methods from FFPE tissues that are in conflict with this research study highlights the differences between paraffin embedded and embalmed tissues. Proteinase $\mathrm{K}$ digestion is required for obtaining sufficient quantiteis of DNA from FFPE tissue, which is in contrast to our results and a similar study utilizing embalmed tissues [22, 27]. Wheeler et al. identified bone marrow as the preferred tissue for DNA isolation utilizing a commercially available FFPE tissue DNA extraction kit, but had highly variable success of amplification due to fixative-mediated DNA degradation [27]. Our modified procedure attempts to alleviate such damage with a resultant higher yield of amplifiable DNA.

This study utilized an established method of restriction enzyme digestion of PCR-amplification of the APOE gene for genotypic analysis [19]. Three of the four cadavers were found to have two alleles of the APOE3 isoform, while the 15/16 female had the APOE2/APOE3 genotype, which is thought to be protective against Alzheimer's. Consistent with these data, the 15/16 female cadaver pathology report indicated the cause of death as failure to thrive at an advanced age, while two of the cadavers had indications of dementia. These results are consistent with previous findings of prevalence and disease implications of APOE isoforms, demonstrating the utilization of this method for the use in genetic research purposes.

Reliable extraction techniques that result in high quantities of amplifiable DNA will impact a number of fields including pathology, forensics, molecular biology, and genetics. The proposed technique offers a potential for incorporation of genetic analysis and primary research post-mortem in curricula, as the need to expand the introduction of molecular techniques in medical school is being recognized [28]. For example, DNA isolation and genotypic analysis could be integrated into cadaver-based anatomy programs, and frequency of genetic markers of disease reported in a crowdsourcing research initiative. Overall, this technique could significantly expand the availability of tissues for genetic analysis post-mortem, while incorporating genomics-based learning into the classroom.

\section{Limitations}

The size of study is limited due to accessibility to tissue.

\section{Additional file}

Additional file 1: Table S1. Variables tested in Method Development. Quantification (ng/ $\mathrm{ll})$, absorbance $260 / 280$ ratio, and DNA electrophoresis gel description of DNA isolated from 4 cadaver donor grey matter cerebellar tissue. Each experiment as performed in duplicate and mean values are indicated. Development of the proposed method included testing of the indicated variables; PBS washes, incubation temperature, and proteinase $K$ treatment. The final method was determined based on a combination of high quantity and quality DNA, yielding large molecular weight fragments.

Authors' contributions

SR conducted and analyzed the data regarding DNA isolation methods. LG conducted and analyzed the data regarding DNA isolation methods, as well as 
the quantitative and qualitative assessment of extracted DNA. All authors read and approved the final manuscript.

\section{Acknowledgements}

The authors would like to acknowledge Nate Kennedy and Justin Golday for their assistance in conducting the presented experiments.

\section{Competing interests}

The authors declare that they have no competing interests.

\section{Availability of data and materials}

The data generated or analyzed during this study are included in this published article.

\section{Consent for publication}

Not applicable.

\section{Ethics approval and consent to participate}

All experiments performed were in compliance with the Purdue University institutional review board regarding the use of DNA from cadavers. Code 45 of Federal Regulations exempts the requirement for IRB review regarding the use of cadaver samples.

\section{Funding}

This project was funded by an undergraduate research grant from the Office of Academic affairs at Purdue University-North Central.

\section{Publisher's Note}

Springer Nature remains neutral with regard to jurisdictional claims in published maps and institutional affiliations.

Received: 21 July 2017 Accepted: 5 December 2017

Published online: 13 December 2017

\section{References}

1. Evison MP, Smillie DM, Chamberlain AT. Extraction of single-copy nuclear DNA from forensic specimens with a variety of postmortem histories. J Forensic Sci. 1997:42(6):1032-8.

2. Brutlag D, Schlehuber C, Bonner J. Properties of formaldehyde-treated nucleohistone. Biochemistry. 1969;8(8):3214-8.

3. Pooniya S, Lalwani S, Raina A, Millo T, Dogra TD. Quality and quantity of extracted deoxyribonucleic Acid (DNA) from preserved soft tissues of putrefied unidentifiable human corpse. J Lab Physicians. 2014;6(1):31-5.

4. Thavarajah R, Mudimbaimannar VK, Elizabeth J, Rao UK, Ranganathan K. Chemical and physical basics of routine formaldehyde fixation. J Oral Maxillofac Pathol. 2012;16(3):400-5.

5. Okello JB, Zurek J, Devault AM, Kuch M, Okwi AL, Sewankambo NK, Bimenya GS, Poinar D, Poinar HN. Comparison of methods in the recovery of nucleic acids from archival formalin-fixed paraffin-embedded autopsy tissues. Anal Biochem. 2010;400(1):110-7.

6. Sambrook J, Russell DW. Purification of nucleic acids by extraction with phenol:chloroform. CSH Protoc. 2006;2006(1):pdb-rot4455.

7. Sato Y, Sugie R, Tsuchiya B, Kameya T, Natori M, Mukai K. Comparison of the DNA extraction methods for polymerase chain reaction amplification from formalin-fixed and paraffin-embedded tissues. Diagn Mol Pathol. 2001;10(4):265-71.

8. Duval K, Aubin RA, Elliott J, Gorn-Hondermann I, Birnboim HC, Jonker D, Fourney RM, Fregeau CJ. Optimized manual and automated recovery of amplifiable DNA from tissues preserved in buffered formalin and alcoholbased fixative. Forensic Sci Int Genet. 2010;4(2):80-8.

9. Ferrer I, Armstrong J, Capellari S, Parchi P, Arzberger T, Bell J, Budka H, Strobel T, Giaccone G, Rossi G, Bogdanovic N, Fakai P, Schmitt A, Riederers P, Al-Sarraj S, Ravid R, Kretzschmar H. Effects of formalin fixation, paraffin embedding, and time of storage on DNA preservation in brain tissue: a BrainNet Europe study. Brain Pathol. 2007;17(3):297-303.
10. Gilbert N, Thomson I, Boyle S, Allan J, Ramsahoye B, Bickmore WA. DNA methylation affects nuclear organization, histone modifications, and linker histone binding but not chromatin compaction. J Cell Biol. 2007;177(3):401-11.

11. Martin-Kearley J, Gow JA, Peloquin M, Greer CW. Numerical analysis and the application of random amplified polymorphic DNA polymerase chain reaction to the differentiation of vibrio strains from a seasonally cold ocean. Can J Microbiol. 1994;40(6):446-55.

12. Paireder S, Werner B, Bailer J, Werther W, Schmid E, Patzak B, CichnaMarkl M. Comparison of protocols for DNA extraction from long-term preserved formalin fixed tissues. Anal Biochem. 2013:439(2):152-60.

13. Shi SR, Cote RJ, Wu L, Liu C, Datar R, Shi Y, Liu D, Lim H, Taylor CR. DNA extraction from archival formalin-fixed, paraffin-embedded tissue sections based on the antigen retrieval principle: heating under the influence of pH. J Histochem Cytochem. 2002;50(8):1005-11.

14. Shi SR, Datar R, Liu C, Wu L, Zhang Z, Cote RJ, Taylor CR. DNA extraction from archival formalin-fixed, paraffin-embedded tissues: heat-induced retrieval in alkaline solution. Histochem Cell Biol. 2004;122(3):211-8.

15. Kim J, Basak JM, Holtzman DM. The role of apolipoprotein E in Alzheimer's disease. Neuron. 2009;63(3):287-303.

16. LaDu MJ, Falduto MT, Manelli AM, Reardon CA, Getz GS, Frail DE. Isoformspecific binding of apolipoprotein $E$ to beta-amyloid. J Biol Chem. 1994;269(38):23403-6.

17. Corder EH, Saunders AM, Strittmatter WJ, Schmechel DE, Gaskell PC, Small GW, Roses AD, Haines JL, Pericak-Vance MA. Gene dose of apolipoprotein E type 4 allele and the risk of Alzheimer's disease in late onset families. Science 1993:261(5123):921-3.

18. Schachter F, Faure-Delanef L, Guenot F, Rouger H, Froguel P, LesueurGinot L, Cohen D. Genetic associations with human longevity at the APOE and ACE loci. Nat Genet. 1994;6(1):29-32.

19. Zivelin A, Rosenberg N, Peretz H, Amit Y, Kornbrot N, Seligsohn U. Improved method for genotyping apolipoprotein E polymorphisms by a PCR-based assay simultaneously utilizing two distinct restriction enzymes. Clin Chem. 1997;43(9):1657-9.

20. Fang SG, Wan QH, Fujihara N. Formalin removal from archival tissue by critical point drying. Biotechniques. 2002;33(3):604-6.

21. Hennig G, Gehrmann M, Stropp U, Brauch H, Fritz P, Eichelbaum M, Schroth W. Automated extraction of DNA and RNA from a single formalin-fixed paraffin-embedded tissue section for analysis of both single-nucleotide polymorphisms and mRNA expression. Clin Chem. 2010;56(12):1845-53.

22. Huijsmans CJ, Damen J, van der Linden JC, Savelkoul PH, Hermans MH. Comparative analysis of four methods to extract DNA from paraffinembedded tissues: effect on downstream molecular applications. BMC research notes. 2010;3(1):239.

23. Torrente MC, Ríos C, Misad C, Ramírez R, Acuña M, Cifuentes L. DNA extraction from formalin-fixed laryngeal biopsies: comparison of techniques. Acta Otolaryngol. 2011;131(3):330-3.

24. Szerlong HJ, Hansen JC. Nucleosome distribution and linker DNA: connecting nuclear function to dynamic chromatin structure. Biochem Cell Biol. 2011;89(1):24-34.

25. Coombs NJ, Gough AC, Primrose JN. Optimisation of DNA and RNA extraction from archival formalin-fixed tissue. Nucleic Acids Res. 1999;27(16):e12.

26. Niland EE, McGuire A, Cox MH, Sandusky GE. High quality DNA obtained with an automated DNA extraction method with 70+ year old formalinfixed celloidin-embedded (FFCE) blocks from the Indiana medical history museum. Am J Transl Res. 2012;4(2):198-205.

27. Wheeler AD, Czado N, Gangitano D. Comparison of DNA yield and STR success rates from different tissues in embalmed bodies. Int J Legal Med. 2017;131:61-6

28. Gerhard GS, Jin Q, Paynton BV, Popoff SN. The anatomy to genomics (ATG) start genetics medical school initiative: incorporating exome sequencing data from cadavers used for Anatomy instruction into the first year curriculum. BMC Med Genom. 2016;9(1):1-62. 